\title{
Do gastrointestinal and respiratory signs and symptoms correlate with the severity of gastroesophageal reflux?
}

\author{
Hakan Uzun ${ }^{1 *}$, Demet Alagoz ${ }^{1}$, Mesut Okur ${ }^{1}$, Bunyamin Dikici ${ }^{1}$, Kenan Kocabay ${ }^{1}$, Dursun Ali Senses ${ }^{1}$, Aybars Ozkan² \\ and Murat Kaya ${ }^{2}$
}

\begin{abstract}
Background: Gastroesophageal reflux (GER) is a disorder that is common by seen in childhood and may lead to severe complications. In this study, we ascertained the incidence of GER among the children who had typical and atypical complaints of GER and whether there was a difference between two groups comparing the findings of 24hour pH-meter.
\end{abstract}

Methods: 39 out of 70 patients with typical and atypical GER symptoms were diagnosed as GER by 24-hour pHmeter monitoring. The patients were divided into three groups, those having gastrointestinal complaints, those having respiratory complaints and those having both gastrointestinal and respiratory symptoms.

Results: Evaluated the GER prevalence in these groups, it was found to be $60 \%$ in the gastrointestinal group, $48.6 \%$ in the respiratory group and $75 \%$ in the mixed group. When $\mathrm{pH}$-meter measurements of GER positive patients were compared within the clinical groups, the fraction of time that $\mathrm{pH}$ was lower than 4 was found to be significantly higher in the mixed group $(p=0.004)$.

Conclusions: The coexistence of gastrointestinal and respiratory symptoms in the patients with GER may be related to the severe reflux.

\section{Background}

Gastroesophageal reflux (GER) is a condition which develops when reflux of stomach contents causes troublesome symptoms and/or complications [1]. GER can result in typical symptoms such as regurgitation, vomiting, heartburn, abdominal and chest pain and failure to thrive [2]. Extraoesophageal manifestations of GER in children (atypical symptoms) include laryngitis, pharyngitis, sinusitis, otitis media, rinit, and pulmonary symptoms such as asthma, chronic cough and recurrent pulmonary aspiration [3-7]. Twenty-four-hour pH-metry is considered the gold standard test for the diagnosis of GER in children [8].

The aim of this study was to determine the prevalence of GER and to evaluate the twenty-four-hour esophageal

\footnotetext{
* Correspondence: uzunhakan2003@yahoo.com

'Department of Pediatrics, Duzce University School of Medicine, 81620 Konuralp, Duzce, Turkey

Full list of author information is available at the end of the article
}

$\mathrm{pH}$-metry of pediatric patients who had typical and atypical GER symptoms.

\section{Methods \\ Patient selections}

From April 2008 to January 2010, 70 children with suspicion of GER (ages between two-seventeen) complaining of heartburn, abdominal pain, recurrent regurgitation, vomiting, failure to thrive, respiratory symptoms such as recurrent respiratory infection, pharyngitis/tonsilitis, otitis, croup, bronchiolitis, persistent cough, wheezing (non related atopy) seen at the Pediatric Outpatient Clinic, Duzce University Medical School Hospital, Duzce, Turkey, were enrolled in the study prospectively. All patients were questioned by the presence of chronic diseases. Demographic and clinical data including patient age, sex, growth parameters such as length and weight were recorded.

\section{Biomed Central}

(C) 2012 Uzun et al; licensee BioMed Central Ltd. This is an Open Access article distributed under the terms of the Creative Commons Attribution License (http://creativecommons.org/licenses/by/2.0), which permits unrestricted use, distribution, and reproduction in any medium, provided the original work is properly cited. 
Examined group of 70 patients was divided into 3 subgroups of patients having gastrointestinal complaints, respiratory complaints, and mixed symptoms (gastrointestinal and respiratory symptoms both). The diagnostic method for GER detection was 24 hour esophageal $\mathrm{pH}$ metry

\section{4-hour pH metry}

The pH metry analysis was performed by an Orion II Ambulatory pH-metry (Medical Measurement Systems Company, Enschede, The Netherlands). The probe was a $2.1-\mathrm{mm}$ outer diameter two sensors placed $5 \mathrm{~cm}$ apart, single use $\mathrm{pH}$ catheter with a reference electrode (Synectics Medical MMS). Prior to the each test, the electrodes were calibrated in buffer solutions (Reagecon Biomedical, Ireland) at $\mathrm{pH} 7$ and $\mathrm{pH}$ 1. This method required placing the $\mathrm{pH}$ probe distally until a clearly acidic $\mathrm{pH}(1.5-2.5)$ was achieved and then slowly withdrawing the probe until the $\mathrm{pH}$ rose to approximately 4.0. At that point, the $\mathrm{pH}$ probe was most likely to be in the esophagogastric junction. The probe was then withdrawn to $3-4 \mathrm{~cm}$ above the level and fixed at that point. The electrode position was always confirmed by a plain chest radiograph. Before placement of the probe the children had to be fasting for at least 6 hours.

Patients received regular feeds. Daily activities and feeding times were recorded during 24 hours.

Data were analyzed by the MMS investigation and diagnostic software v8.7, for Windows.

All $24 \mathrm{hr}$ pH-metry recordings were manually analyzed and all data underwent visual validation. The DeMeester score was used to define pathological GER [9] recorded by the distal sensor. The following parameters were compared:

1. Number of reflux episodes

2. Number of reflux episodes longer than 5 minutes in 24 hours

3. Longest episode of reflux (in minutes)

4. Fraction of time with $\mathrm{pH}$ lower than 4 was considered abnormal if greater than $5 \%$.

5. Reflux index (number of refluxes per hour).

A diagnosis of GER was established when reflux index was greater than $>4$, or DeMeester score was higher than 14.7, or pathological reflux was considered as at least 1 reflux episode with a $\mathrm{pH}$ below 4 in the proximal sensor.

\section{Statistics}

Frequency counts and cross-tabs were used to describe nominal variables. Chi square test was used for the analyses of categorical variables. Man Whitney- $U$ test was used for analyses of numeric variables. Kruskal Wallis $\mathrm{H}$ was used for analyzing multiple groups and Boferroni adjusted Man Whitney- $U$ test was used for multiple comparisons. Statistical analyses were carried out using the SPSS 10.0 for Windows. $P$ values $<0.05$ were considered significant.

\section{Ethical considerations}

The study protocol was approved by the Ethics Committee of Duzce University Hospital. All subjects gave written informed consent.

\section{Results}

Seventy patients (40 males, 30 females) were enrolled in the study. Demographic Data for the 70 patients was summarized in (Table 1). Frequency of clinical symptoms in patients were such as gastrointestinal $35.7 \%$ (n: 25), respiratory $52.9 \%$ (n: 37), mixed $11.4 \%$ (n: 8) (Table 2). According to the $24 \mathrm{hr} \mathrm{pH}$ metry results revealed GER in 39 patients. While GER was detected in 25 patients $(64.1 \%)$ by the only distal probe, it was detected in 14 patients $(35.8 \%)$ by the both distal and proximal probes ( 6 of out 14 patients were included in respiratory group, 5 gastrointestinal group and 3 mixed group).

The prevalence of GER was found $55.7 \%$ among the patients. According to the clinical groups, the prevalence of GER was found to be $60 \%$ in the gastrointestinal group, $48.6 \%$ in the respiratory group, and $75 \%$ in the mixed group.

According to the comparisons of $\mathrm{pH}$ meter measurements of GER positive patients in the clinical groups, the in-group median of the fraction of time that $\mathrm{pH}$ was lower than 4 were found to be statistically significant. That difference was arisen from the high value in the mixed group. No statistical difference was significantly found between the groups for other parameters (Table 3).

The weight and height percentiles of 6 GER positive patients were found to be low. However, no statistically

Table 1 Demographic data for the 70 patients included in the study

\begin{tabular}{llll}
\hline Variables & GER positive & GER negative & $\boldsymbol{P}$ \\
\hline Age (median) & $11(2-17)$ & $11(3-17)$ & $0,622^{\infty}$ \\
\hline Male/Female $(\mathrm{n})$ & $24 / 15$ & $16 / 15$ & $0.204^{*}$ \\
\hline Vomiting $(\mathrm{n})$ & 8 & 3 & $0.255^{*}$ \\
\hline Abdominal pain(n) & 9 & 4 & $0.329^{*}$ \\
\hline Nausea (n) & 8 & 9 & $0.353^{*}$ \\
\hline Regurgitation $(\mathrm{n})$ & 16 & 9 & $0.388^{*}$ \\
\hline Hematemesis $(\mathrm{n})$ & 1 & 0 & $0.207^{*}$ \\
\hline Chronic cough $(\mathrm{n})$ & 26 & 21 & $0.857^{*}$ \\
\hline Non atopic Asthma $(\mathrm{n})$ & 21 & 19 & $0.676^{*}$ \\
\hline${ }^{*}$ Man Whitney-U & & & \\
$*$ Chi-square test & & &
\end{tabular}


Table 2 Distribution of clinical symptom of GER positive and negative patients

\begin{tabular}{lllll}
\hline & Clinical symptoms & & \multicolumn{2}{c}{ Total } \\
\hline $\mathbf{n}(\%)$ & Gastrointestinal Group 1 $\mathbf{n}(\%)$ & Respiratory Group 2 $\mathbf{n}(\%)$ & Mixed Group 3 $\mathbf{n ( \% )}$ & $31(44.3)$ \\
\hline GER negative & $10(14.3)$ & $19(27.2)$ & $2(2.8)$ & $39(55.7)$ \\
\hline GER positive & $15(21.4)$ & $18(25.7)$ & $6(8.6)$ & $70(100)$ \\
\hline Total & $25(35.7)$ & $37(52.9)$ & $8(11.4)$ & \\
\hline
\end{tabular}

significant difference was found between both groups in comparison with the weight and height percentiles of GER negative and positive patients.

\section{Dicussion}

In our study, 39 of 70 patients (55.7\%) who were admitted to hospital with various complaints were diagnosed GER by 24-hour pH monitoring. The distribution of the patients with GER by the initial symptoms at the time of admission was summarized in Table 1, 2 .

GER occurs frequently during the first year of life with a peak incidence of $67 \%$ at 4 months of age. Also, at least one episode of reflux per day occurs in $50 \%$ of infants who are between the ages of birth and 3 months. GER is considered physiologic in early childhood period and disappears in the second year of life. The prevalence of GER was found to be $1.8-8.2 \%$ in epidemiological studies among children of 3-17 year of age groups [10]. The frequency of GER was found as 37 to $52.3 \%$ in children who were performed by 24-hour esophageal $\mathrm{pH}$ monitoring suspected GER disease [11,12]. In our study GER was found to be $55.7 \%$ in patients. High frequency of GER was associated with the severity of the disease.

The frequency of GER was reported to be $25 \%$ to $80 \%$ among the children with recurring respiratory tract disease in several previous studies, [13]. In our study, the respiratory system symptoms were the most frequently seen finding seen in the patients diagnosed with GER. Respiratory system symptoms were found in 24 cases of whom 18 from respiratory group and 6 from mixed group and it consisted of $60 \%$ of 39 patients. The association between GER and respiratory system has been known for a long time. Both esophagus and bronchial tree originated from the same primary nourishing path and were stimulated by the vagus nerve [14]. Khoshoo et al. reported that they found a significant increase in GER incidence in children with asthma. Asthma was found in $50 \%$ to $60 \%$ of the children with GER [5]. In our study, it was found that 24 out of 39 GER positive patients $(61 \%)$ had chronic cough and non atopic asthma. Our results were found consistently with the literature.

Several mechanisms have been postulated by which GER might cause coughing. Aspiration of gastric juices containing acid, pepsin, bile acids and duodenal pancreatic enzymes, is considered to be an important mechanism in the etiology of reflux-related cough. Pharyngeal $\mathrm{pH}$ recording that demonstrated micro-aspiration of gastric contents into the pharynx favored this hypothesis [15]. In the past, detection of lipid-laden macrophages in bronchoalveolar lavage fluid or sputum has been used as possible a marker for aspiration. Studies show that lipid-laden alveolar macrophages are present in $85 \%$ of children with chronic respiratory tract disorders and GER [16,17]. A vagal reflex arc originating from the distal esophagus after either exposure to acid or esophageal distention can cause coughs [18-20]. Acidification of the esophagus can activate local axonal reflexes which can cause inflammation in the airway. A study of Patterson et al. showed that the presence of acid in the esophagus in asthma and chronic cough patients causes releases of tachykinins such as substance $\mathrm{P}$ and neurokinin $\mathrm{A}$ into the lungs where they cause bronchoconstriction and airway micro vascular leakage [21].

According to the given $\mathrm{pH}$-meter monitoring parameters of GER positive patients in our study, we observed that the parameters were generally high in

Table 3 GER positive $\mathrm{pH}$ data by clinical groups

\begin{tabular}{|c|c|c|c|c|}
\hline $\mathrm{pH}$ metry parameter & $\begin{array}{l}\text { Group } 1 \text { gastrointestinal median } \\
\text { (min max) }\end{array}$ & $\begin{array}{l}\text { Group } 2 \text { respiratory median } \\
\text { (min- } \max \text { ) }\end{array}$ & $\begin{array}{l}\text { Group } 3 \text { mixed median } \\
\text { (min-max) }\end{array}$ & $P$ \\
\hline $\begin{array}{l}\text { Number of reflux episodes greater than } 5 \\
\text { minutes in } 24\end{array}$ & $2(1-21)$ & $3(0-22)$ & $2.5(2-9)$ & 0.682 \\
\hline Number of reflux episodes in 24 hours & $74(40-426)$ & $61.5(20-271)$ & $92(74-197)$ & 0.286 \\
\hline Duration of the longest reflux episode & $20(10-260)$ & $23(10-146$ & $24(7-29)$ & 0.919 \\
\hline The reflux index & $8(4-77.8)$ & $7.8(5-65)$ & $10.3(7.8-16)$ & 0.576 \\
\hline $\begin{array}{l}\text { Fraction of time with } \mathrm{pH} \text { lower than } 4 \mathrm{pH} \\
>5(\%)\end{array}$ & $2.7(0-6)$ & $2(0-10.9)$ & $6(4.7-11.5)$ & 0.004 \\
\hline
\end{tabular}


gastrointestinal and mixed groups. The reasons of high GER positivity in the mixed groups might be that of $\mathrm{pH}$-meter parameters, the number of reflux in 24 hours, the number of reflux prolonged over 5 minutes in 24 hours, and the time interval when esophagus $\mathrm{pH}$ was under 4 were high in the mixed group in comparison with other groups. The children in the mixed group, who have both respiratory and gastrointestinal symptoms, are at higher risk of GER. In a study carried out with children population, it was denoted that patients with mixed respiratory and gastrointestinal symptoms had more severe disease than did patients with isolated respiratory disorders indicates that clinical symptoms are a good marker of reflux severity in children [21]. In our study we found similar results.

The limitations of our study are the small number of the patients. The established incidence of GER in examined subgrups of patients is limited only to those with the acidic GER (pH-metry detected). In the remaining examined subjects who did not show the occurrence of acid reflux the presence of alkaline refluks should be suspected. Combined mulitichannel intraluminal impedance and $\mathrm{pH}$ measurement should be used. The examined group with mixed GER symptoms is numerically small. The severity of GER should be confirmed by application of diagnostic methods of pH-metry, gastroscopy (eosaphagitis?) and nature of the clinical symptoms observed in the patients. The study should be continued in the future, according to the above remarks, with MI Impedance and pH-metry application.

\section{Conclusion}

24-hour $\mathrm{pH}$-meter is the gold standard non-therapeutic diagnostic method for the diagnosis of GER in children. An important conclusion drawn from the study is that coexistence of gastrointestinal and respiratory symptoms in the patients with GER confirm the severity of reflux.

\section{Author details}

${ }^{1}$ Department of Pediatrics, Duzce University School of Medicine, 81620 Konuralp, Duzce, Turkey. ${ }^{2}$ Department of Pediatric Surgery, Duzce University School of Medicine, Duzce, Turkey.

\section{Authors' contributions}

$\mathrm{HU}$ performed the analysis, writing and preparation of manuscript. DA contributed to data collection. MO contributed to the writing of the manuscript. BD literature review and manuscript preparation. KK substantially contributed to study conception and design, revision of the manuscript. DAS substantially contributed to study conception and design, revision of the manuscript. AO contributed to analysis and interpretation of data, revision of the manuscript, MK contributed to analysis and interpretation of data, revision of the manuscript. All authors read and approved the final manuscript.

\section{Competing interests}

The authors declare that they have no competing interests.
Received: 30 November 2011 Accepted: 21 March 2012

Published: 21 March 2012

\section{References}

1. Rudolph CD, Mazur LJ, Liptak GS, Baker RD, Boyle JT, Colletti RB, Gerson WT, Werlin SL: Guidelines for evaluation and treatment of gastroesophageal reflux in infants and children: recommendations of the North American Society for Pediatric Gastroenterology and Nutrition. J Pediatr Gastroenterol Nutr 2001, 32(Suppl 2):1-31.

2. Waring JP, Feiler MJ, Hunter JG, Smith CD, Gold BD: Childhood gastroesophageal reflux symptoms in adult patients. J Pediatr Gastroenterol Nutr 2002, 35:334-338.

3. El-Serag HB, Gilger M, Kuebeler M, Rabeneck L: Extraesophageal associations of gastroesophageal reflux disease in children without neurologic defects. Gastroenterol 2001, 121:1294-1299.

4. Zalesska-Krecicka M, Krecicki T, Iwanczak B, Blitek A, Horobiowska M: Laryngeal manifestations of gastroesophageal reflux disease in children. Acta Otolaryngol 2002, 122:306-310.

5. Khoshoo V, Le T, Haydel RM Jr, Landry L, Nelson C: Role of gastroesophageal reflux in older children with persistent asthma. Chest 2003, 123:1008-1013.

6. Ay M, Sivasli E, Bayraktaroglu Z, Ceylan H, Coskun Y: Association of asthma with gastroesophageal reflux disease in children. J Chin Med Assoc 2004, 67:63-66.

7. Cinquetti M, Micelli S, Voltolina C, Zoppi G: The pattern of gastroesophageal reflux in asthmatic children. J Asthma 2002, 39:135-142.

8. Sondheimer JM: Continous monitoring of distal esophageal $\mathrm{pH}: \mathrm{A}$ diagnostic test for gastroesophageal reflux in infants. J Pediatr 1980, 96:804-807.

9. Johnson LF, Demeester TR: Twenty-four hour $\mathrm{pH}$ monitoring of the distal esophagus. A quantitative measure of the distal esophagus. Am J Gastroenterol 1974, 62:325-332.

10. Nelson SP, Chen EH, Syniar GM, Kaufer- Christoffel K: Prevalence of symptoms of gastroeophageal reflux during childhood: a pediatric practice-based survey. Pediatric Practice Research Group Archives of Pediatric Adolescent Medicine 2000, 154:150-154.

11. Pilic D, Fröhlich T, Nöh F, Pappas A, Schmidt-Choudhury A, Köhler H, Skopnik H, Wenzl TG: Detection of Gastroesophageal Reflux in Children Using Combined Multichannel Intraluminal Impedance and $\mathrm{pH}$ Measurement: Data from the German Pediatric Impedance Group. J Pediatr 2011, 158:650-654.

12. Semeniuk J, Kaczmarski M: 24-hour esophageal pH-monitoring in children suspected of gastroesophageal reflux disease: analysis of intraesophageal $\mathrm{pH}$ monitoring values recorded in distal and proximal channel at diagnosis. World J Gastroenterol 2007, 13:5108-5115.

13. Tucci F, Resti M, Fontana $R$, Novembre $E$, Lami CA, Vierucci $A$ : Gasroesophageal reflux and bronchial asthma: prevalence and effect of cisapride therapy. J Pediatr Gastroenterol Nutr 1993, 17:265-270.

14. Calabrese F, Rizzo S, Giacometti C, Panizzolo C, Turato G, Snijders D, Lunardi F, Vadori M, Valente M, Saetta M, Barbato A: High viral frequency in children with gastroesophageal reflux-related chronic respiratory disorders. Pediatr Pulmonol 2008, 43:690-696.

15. Oelschlager BK, Quiroga E, Isch JA, Cuenca-Abente F: Gastroesophageal and pharyngeal reflux detection using impedance and 24-hour $\mathrm{pH}$ monitoring in asymptomatic subjects: defining the normal environment. J Gastrointest Surg 2006, 10:54-62.

16. Ahrens $P$, Noll C, Kitz R, Willigens $P$, Zielen S, Hofmann D: Lipid-laden alveolar macrophages (LLAM): a useful marker of silent aspiration in children. Pediatr Pulmonol 1999, 28:83-88.

17. Parameswaran K, Anvari M, Efthimiadis A, Kamada D, Hargreave FE, Allen CJ: Lipid-laden macrophages ininduced sputum are a marker of oropharyngeal reflux and possible gastric aspiration. Eur Respir J 2000, 16:1119-1122.

18. Ing AJ, Ngu MC, Breslin AB: Pathogenesis of chronic persistent cough associated with gastroesophageal reflux. Am J Respir Crit Care Med 1994, 149:160-167.

19. Irwin RS, Zawacki JK, Curley FJ, French CL, Hoffman PJ: Chronic cough as the sole presenting manifestation of gastroesophageal reflux. Am Rev Respir Dis 1989, 140:1294-1300. 
20. Patterson RN, Johnston BT, Ardill JE, Heaney LG, McGarvey LP: Increased tachykinin levels in induced sputum from asthmatic and cough patients with acid reflux. Thorax 2007, 62:491-495.

21. Gorenstein A, Levine A, Boaz M, Mandelberg A, Serour F: Severity of acid gastroesophageal reflux assessed by $\mathrm{pH}$ metry: is it associated with respiratory disease? Pediatr Pulmonol 2003, 36:330-334.

Pre-publication history

The pre-publication history for this paper can be accessed here: http://www.biomedcentral.com/1471-230X/12/22/prepub

doi:10.1186/1471-230X-12-22

Cite this article as: Uzun et al:: Do gastrointestinal and respiratory signs and symptoms correlate with the severity of gastroesophageal reflux?

BMC Gastroenterology 2012 12:22.

Submit your next manuscript to BioMed Central and take full advantage of:

- Convenient online submission

- Thorough peer review

- No space constraints or color figure charges

- Immediate publication on acceptance

- Inclusion in PubMed, CAS, Scopus and Google Scholar

- Research which is freely available for redistribution

Submit your manuscript at www.biomedcentral.com/submit 